\title{
El sobreendeudamiento crediticio y su implicancia en las instituciones financieras y en la sociedad
}

Mg. Julio Aquije Milanta

\section{Antecedentes de la Investigación}

El logro del bienestar como de la igualdad, en sus diferentes manifestaciones (sociales, económicas, políticas y culturales), constituye una búsqueda constante de la Sociedad y de los Estados. Ha sido inicialmente un tema de filósofos como Platón, Tomás Moro, Campanella, Bacón, y otros finalizando con Proudhon (1809-1865), quienes en su correspondiente momento, se imaginaron lo que era el Estado en una utopía. En él, según Arrieta (2010), " ... se alcanza un estado de perfecta justicia, la satisfacción de las necesidades que ahora son el motivo para el vivir." En el pensamiento de Platón, lograr el bienestar de la gente constituye el objetivo de toda forma de gobierno, como personificación del estado.

A partir de estas ideas, el desarrollo y el logro de bienestar han sido y continúa siendo el motor de todos los estados y de las diferentes formas de gobierno. Es la aspiración de quienes se adhieren a las ideas y prácticas estatistas (mercado controlado) y de quienes se adhieren a las ideas y prácticas capitalistas (libre mercado), como las expresiones de modelos de sociedad. Respecto a la morosidad y sobreendeudamiento en el Sistema Financiero Nacional, Adrian Castañeda en su tesis para el grado de Magister en Economía: "Factores determinantes de la morosidad del Sistema Bancario Peruano - 2001-2007" (2008), ya señalaba que los bancos y particularmente las empresas micro financieras, habrían de flexibilizar sus exigencias con la finalidad de incrementar su cartera de colocaciones y obtener mayores ganancias. Refiere que tal flexibilidad ha permitido acceder al crédito a mayor número de consumidores, ingresar a la economía formal a mayor número de empresas informales, además de personas sin la suficiente solvencia para cubrir sus compromisos en los plazos establecidos, lo que podría generar la constitución de cartera morosa proveniente del sobreendeudamiento del consumidor. 
No obstante los reportes del ente supervisor (SBS), indican que los índices de morosidad a marzo del 2016, si bien muestran un ligero incremento con respecto al mes de febrero ubicándose, en $1.73 \%$ (desde el 1.67\%) sigue siendo la más baja de América latina.

De acuerdo a investigaciones realizadas por el autor Ignacio Larraechea (Decano de la Facultad de Ciencias Económicas de la Universidad de Chile - 2011), las personas llegarían progresivamente al sobreendeudamiento, a través de lo que denomina el "facilismo del crédito" o por el "autooscurecimiento del gasto". Según el investigador, al pagarse con tarjetas de crédito, la persona no toma real conciencia que ha adquirido una obligación a cambio del bien adquirido.

En Chile, según el artículo del Foro ciudadano: "Vivir para pagar"(2006) de la Universidad de Chile, el sobreendeudamiento se había convertido en un "problema de salud pública", pues afectaba el comportamiento y la emocionalidad de las personas. A la fecha, sin embargo no se han publicado nuevos artículos dando cuenta del manejo de este problema.

El Crédito es el mecanismo fundamental de conversión de capital en dinero, mediante el pago de un interés establecido en el contrato consensual entre quien provee el dinero y el beneficiario, cuya finalidad "...consiste en hacer posible una capacidad amplia de cambio en el tráfico mercantil 0 financiero, permitiendo la adquisición de aquellos medios necesarios para el mejor desarrollo de una determinada actividad económica...".

Este producto debe su popularidad a las características otorgadas para la satisfacción idónea de las necesidades personales de liquidez y a su adecuación al flujo de caja del consumidor.

No obstante tan alto nivel de libertad operativa, sumado a la falta de cultura financiera, son factores que confunden al consumidor y lo llevan a un abismo de consumismo que termina en la asunción de deudas mayores a su capacidad de pago, entendida como el total de ingreso recibido frente a las obligaciones asumidas por el consumidor con el sistema financiero y/o comercial; en una palabra al sobreendeudamiento.

Las familias buscan maximizar su utilidad en la producción de los bienes y servicios que requiere su hogar (los que no se comercializan en el mercado) pero que para producirlos se requiere de otros bienes y servicios que se producen en el mercado. Este flujo de necesidades, dinamiza el mercado y contribuye al crecimiento económico.

El crecimiento económico de los últimos años ha tenido como uno de sus efectos, la ampliación del crédito a sectores antes excluidos del sistema financiero formal. Ella se traduce en crecientes niveles de colocaciones de los bancos, vía préstamos de libre disponibilidad y de tarjetas de crédito; es decir, sector de Crédito Minorista de Consumo - Revolventes.

Reportes del ente regulador, la Superintendencia de Banca y Seguros y AFP's (SBS), muestran que las colocaciones en créditos de consumo históricamente pasaron de $11.94 \% \%$ en el año 2003 al $18.90 \%$ en el 2007; este se ha incrementado en $35.1 \%$ en el año 2008 con respecto al 2007 según las estadísticas del ente supervisor SBS. Este crecimiento, según el propio ente supervisor (SBS), se explicaría por el proceso de "bancarización de la economía". 
El Instituto "Apoyo", en su Informe Gerencial de Marketing 2008(2009), reporta que el acceso al sistema financiero y bancario, con ello a la economía formal, es transversal para todos los niveles socios económicos de Lima:

Al periodo investigado 2015-2016, el 41\% de la población tiene alguna cuenta o producto financiero o bancario; $44 \%$ del nivel socioeconómico C; $26 \%$ del nivel $D$ y $11 \%$ del nivel $E ; 19 \%$ tiene cuenta de ahorros, de ellos $17 \%$ del nivel $C, 8 \%$ del nivel $D$ y $2 \%$ del nivel $E_{;} ; 16 \%$ tiene crédito o préstamos personal, $18 \%$ del nivel $C, 13 \%$ del nivel $D$ y $9 \%$ del nivel $E_{;} 11 \%$ tiene tarjeta de crédito de algún banco, $7 \%$ del nivel $\mathrm{C}, 3 \%$ del nivel $\mathrm{D}$ y sólo $1 \%$ del nivel $\mathrm{E}$.

En suma, los reportes del ente supervisor SBS, dan cuenta de un incremento sostenido de la penetración financiera en todos los niveles de la población con mayor énfasis a partir de la Ley de bancarización puesta en vigencia por el gobierno a partir del 2010, notoriamente acelerado durante el periodo en estudio.

Es a través del Crédito que los países, las empresas y las familias, adquieren capacidad económica para financiar sus proyectos de crecimiento, de progreso para lograr sus metas de desarrollo y de bienestar respectivamente.

\section{Base Teórica}

Situaciones similares se exponen en los portales web que tratan el tema en España, México y los Estados de Norte América. Todos estos países existe preocupación por el efecto negativo que tiene el sobreendeudamiento sobre la productividad laboral, la inclusión social y, la calidad de la cartera de las instituciones financieras. Asociado al concepto de desarrollo como proceso integral, progresivo hacia la modernidad, se configura el concepto de desarrollo social. Tiene su fundamento en la necesidad de corregir las grandes desigualdades de oportunidad para acceder a los bienes y servicios necesarios al bienestar entre las familias de los países pobres, comparado con las familias de los países ricos. El concepto de desarrollo social hace énfasis en el crecimiento económico, uno de sus ejes, no sólo como acumulación de riqueza, sino en su alineamiento a la satisfacción de las necesidades de las personas, su contribución a la reducción de las desigualdades y a la erradicación de la pobreza absoluta. Todaro, citado por Solano (2010-2012), señala que "...el desarrollo social tiene elementos característicos como: formación de capacidades institucionales y personales, fortalecimiento de la democracia, gobernabilidad, derechos humanos y ciudadanía...," entre otros; Karen M Mokate y José Jorge Saavedra (INDES/BID - 2004) entienden por desarrollo social "... un proceso dinámico, multidimensional, que conduce a mejoras sostenibles en el bienestar de los individuos, familias, comunidades y sociedades, en un contexto de justicia y equidad...".

Alrededor de este concepto se ha formulado un modelo de desarrollo que ha sido implementado, bajo diferentes formas especialmente en países nórdicos como Suecia, Noruega y Finlandia; fue el propósito de los países socialistas de la Europa del este y Cuba, y ha tenido influencia en toda Europa y en la política americana hasta los años 80 e influye significativamente en el pensamiento y acciones de las diferentes corrientes políticas y países del mundo. Como modelo de desarrollo hace énfasis en la intervención del Estado para implementar políticas relacionadas 
con el establecimiento de un ingreso mínimo, protección social frente al desempleo, enfermedad y muerte, así como programas sociales previsionales, de seguridad social y de educación como derecho de los ciudadanos que permita un estándar mínimo de bienestar a lo largo de su vida. En esta perspectiva el Bienestar está asociado a un ingreso que permita que la persona satisfaga sus necesidades de alimentación, vestimenta, recreación y cultura y al uso de los programas del Estado para los problemas de salud y educación.

Como se expuso anteriormente, desde la perspectiva teórica de Ramón Casilda Béjar(2014), acerca de la productividad y la acumulación económica como mecanismo de costeo de la satisfacción de las necesidades individuales de bienestar, el sobreendeudamiento correspondería a un estado en el que la productividad de la persona llega a ser "deficiente", de un modo sostenido, que no le permite asumir el costo de su bienestar. En tal situación la persona, según su condición económica precedente, podría tener una movilidad social descendente, pasando a formar parte de los grupos empobrecidos y no elegibles para contratar con el sistema financiero.

En Perú tal situación se evidencia en los casos de ajustes estructurales como la reforma agraria y otras reformas que afectaron la propiedad y el ingreso. Muchos de los propietarios (agricultores, industriales, comerciantes, etc.) endeudados o con ventas a crédito, al momento de la reforma, lo perdieron todo y pasaron a la situación de pobres o en todo caso en un nivel socioeconómico menor; el ejemplo más reciente de tales eventos, es el empobrecimiento de las clases medias, como consecuencia de los ajustes estructurales de los años 80 y los 90 de cuya reconstitución da cuenta el periodista y antropólogo peruano Jaime De Althaus ("La Revolución Capitalista en el Perú"-2008).

Otro efecto del sobreendeudamiento tiene que ver con la perdida de aquellas capacidades que, según Martha C. Nussbaum (2006), son necesarias para el logro de una vida digna, de bienestar. Desde la perspectiva de esta autora, la persona sobre endeudada sería "incapaz" de tener propiedades, muebles o inmuebles e incluso de ejercer derecho de propiedad sobre los mismos; también podría ser sujeto de persecución y captura injustificadas; otra de la capacidad que se ve afectada por el sobreendeudamiento es la de trabajar como un ser humano, ejercitando la razón práctica y participando en relaciones significativas de mutuo reconocimiento con otros trabajadores; igualmente queda mermada su capacidad para contratar con las instituciones que participan en el Sistema Financiero Nacional.

\section{Definición de Términos}

Superintendencia de Banca Seguros y AFP; Organismo regulador del Sistema Financiero Nacional, de Seguros y Reaseguros y de Administradoras de Fondo de Pensiones que operan en el Sistema Financiero Nacional. (SBS).

Sobreendeudamiento; Incapacidad sostenida para hacer frente a las obligaciones periódicas del pago de deudas y los gastos mensuales normales, pudiendo llegar a una situación de insolvencia que conduce a la quiebra de la economía familiar. El sobreendeudamiento implica un desbalance entre el gasto y la capacidad para generar ingresos, obligando a la búsqueda de financiamientos adicionales a los regulares (el salario). 
Créditos de Consumo: Créditos otorgados a personas naturales con la finalidad de atender necesidades personales y/o familiares, como puede ser el pago de bienes, servicios o gastos no relacionados con la actividad empresarial.

Créditos de Consumo - Revolventes: Son aquellos créditos en los que se permite que el saldo fluctúe en función de las decisiones del deudor. Incluye las modalidades de avances en cuenta corriente, tarjetas de crédito, sobregiros en cuenta corriente, préstamo revolvente y otros créditos revolventes. Asimismo, se consideran dentro de este tipo de crédito los productos que permiten reutilizaciones parciales, es decir, que tienen un componente revolvente y otro no revolvente. (R-SBS n¹1356-2008)

Cartera Atrasada: Es la suma de los créditos vencidos y en cobranza judicial.

Cartera de Alto Riesgo: Es la suma de los créditos reestructurados, refinanciados, vencidos y en cobranza judicial.

Cartera Pesada: Corresponde a los créditos directos e indirectos con calificaciones crediticias del deudor de deficiente, dudoso y pérdida.

Crédito Castigado: Créditos clasificados como pérdida, íntegramente provisionados, que han sido retirados de los balances de las empresas. Para castigar un crédito, debe existir evidencia real de su irrecuperabilidad o debe ser por un monto que no justifique iniciar acción judicial o arbitral.

Tarjeta de Crédito: Modalidad que comprende los créditos concedidos a los usuarios de las tarjetas de crédito, para adquirir bienes o servicios en establecimientos afiliados o hacer uso de disposición en efectivo, bajo condiciones establecidas contractualmente.

Provisión de la Cartera de Créditos: Corresponde a las provisiones constituidas sobre los créditos directos. Es la cuenta que ajusta el valor de la cartera de créditos en función de la clasificación de riesgo del deudor.

Riesgo de Crédito: La posibilidad de pérdidas por la incapacidad o falta de voluntad de los deudores, contrapartes, o terceros obligados para cumplir sus obligaciones contractuales registradas dentro o fuera de balance.

Riesgo de Mercado: Posibilidad de pérdidas en posiciones dentro y fuera de balance derivadas de fluctuaciones de los precios de mercado.

Riesgo de Operación: La posibilidad de pérdidas debido a procesos inadecuados, fallas del personal, de la tecnología de información, o eventos externos. Esta definición incluye el riesgo legal, pero excluye el riesgo estratégico y de reputación.

Riesgo de Precio: Posibilidad de pérdidas derivadas de fluctuaciones de los precios de los valores representativos de capital. 
Riesgo de Tasa de Interés: Posibilidad de pérdidas derivadas de fluctuaciones de las tasas de interés. (Mercado, SBS).

\section{Hipótesis de Investigación}

Se busca con este análisis lograr una comprensión cualitativa sobre el marco legal existente emitido por el ente regulador (SBS) sobre los temas de investigación; la colocación del Producto Financiero Crédito Minorista de Consumo - Revolvente por parte de las instituciones financieras que operan en nuestro país; la aplicación del marco normativo y su efecto en el fenómeno del sobreendeudamiento; y, la experiencia de sobreendeudamiento del consumidor frente a este producto financiero en el mercado.

\section{Hipótesis General.}

Se plantea como hipótesis general para la investigación:

Las Instituciones Financieras otorgantes del producto financiero Crédito Minorista de Consumo - Revolvente cuentan con normativa suficiente para una correcta administración de estrategias efectivas que les permiten contrarrestar los indicadores de sobreendeudamiento crediticio del consumidor financiero, así como de la propia utilidad del ejercicio. Actuando como marco normativo y operativo que envuelve al sistema en su conjunto, tanto a las instituciones financieras otorgantes como la relación que se mantiene con el usuario y su comportamiento en el sistema.

\section{Hipótesis Específicas.}

Se desprenden como Hipótesis Específicas:

1) La Superintendencia de Banca, Seguros y Administradoras de Fondos de Pensión (SBS), proporciona el marco normativo general del comportamiento de los actores involucrados en la colocación de créditos, en el presenta caso, del Producto Financiero Crédito Minorista de Consumo - Revolvente en las instituciones financieras

2) Las Instituciones Financieras otorgantes elaboran políticas internas de aplicación del marco normativo, por tipo de crédito, por clasificación del cliente para el control de provisiones ocasionadas por el sobreendeudamiento creditico para mejorar la utilidad del ejercicio.

3) El sector de consumidores del Producto Financiero Crédito Minorista de Consumo - Revolvente asume obligaciones superiores a sus ingresos netos trasparentando carencias de educación financiera suficiente que le imposibilitan determinar la peligrosidad del sobreendeudamiento financiero al que se somete.

El presente artículo es un extracto de la tesis "Reglamentación y Estrategia Institucional para evitar el sobreendeudamiento en el Sector de Créditos Minorista de Consumo - Revolvente en Lima Metropolitana 2015-2016", cuya finalidad es diagnosticar los factores que explican el efecto del sobreendeudamiento producido por el producto de Créditos Minorista de Consumo -Revolvente, Lima Metropolitana, en el ámbito en que se ha ejecutado la investigación años 2015-2016 y el 
Marco Legal vigente tanto para las instituciones financieras peruanas como para las personas usuarias - consumidor de este producto.

La fuerte competencia entre las entidades bancarias está ocasionando que centren su atención en productos de financiamiento más rentables para la institución, por lo general, por los márgenes de ganancia que generan, por el universo de clientes y segmentos para explotar, y por la fácil accesibilidad para obtenerlos, hace que en los últimos 16 años haya un aumento progresivo en el producto de Créditos Minorista de Consumo - Revolvente. Si esto no es controlado y los hogares caen en una situación de sobreendeudamiento, podemos enfrentarnos a un problema socioeconómico muy grave.

Así mismo, el fácil acceso a los Créditos Minorista de Consumo - Revolvente producen un impacto positivo tanto en el nivel de vida de las personas como en la economía del país. Por otro lado, la experiencia en todos estos años nos hace ver que también producen situaciones negativas como el crecimiento del sobreendeudamiento cuando los clientes se enfrentan a deudas insostenibles, lo que ocasiona que se obtengan resultados poco alentadores para las instituciones financieras y consecuencias nefastas para las personas y sus familias.

Dicho esto, existe una interrogante general ¿Cuáles son los efectos del sobreendeudamiento producido por el producto de Créditos Minorista de Consumo - Revolvente, tanto para el sistema financiero nacional como para el consumidor?

A través de un análisis se logra establecer que los factores importantes del sobreendeudamiento en el Producto de Créditos Minorista de Consumo - Revolvente se manifiestan en:

a) Pérdidas en la rentabilidad esperada, en los niveles patrimoniales, incremento en las provisiones contables y mala calidad de la cartera crediticia que se refleja en los indicadores de gestión de las instituciones financieras esto como resultado del afán por alcanzar el liderazgo y rentabilizar el sector;

b) Consumidores con capacidad de pago mermada por adquirir mayor compromiso con deudas hacen que su ingreso promedio de renta no cubra sus necesidades básicas ni los nuevos compromisos de deuda logrando que en el tiempo no puedan cumplir dentro de los plazos establecidos ni las condiciones esperadas lo que conlleva a obtener una clasificación adversa como historial crediticio de pago.

Se habla de "sobreendeudamiento crediticio" cuando el consumidor contrata obligaciones financieras que exceden su capacidad de pago; es decir, sus ingresos no son suficientes para cubrir sus necesidades básicas ni los compromisos derivados de créditos u obligaciones contraídas con el sistema financiero así como con empresas comerciales, pudiendo llegar a niveles de insolvencia total.

Los efectos se extienden tanto al Sistema Financiero Nacional como al consumidor mismo. Existe deterioro de la cartera del producto Crédito Minorista de Consumo - Revolvente en el sistema financiero en un gran número de instituciones financieras, generando pérdidas por incremento de 
provisiones, venta y castigo de la misma; por otro lado están los consumidores que por falta de una cultura financiera, obtienen créditos que exceden su capacidad de pago y llegan a perder sus bienes acumulados en el tiempo y/o a ser elegibles por el mercado financiero.

La experiencia genera una alerta vigilante sobre el aparente crecimiento desmedido de los productos financieros de créditos, especialmente el de Consumo - Revolvente, lo que pudiera ocasionar grandes riesgos en pérdidas millonarias tanto a las instituciones financieras como al consumidor; entonces estaríamos hablando de un "sobreendeudamiento generalizado", incrementando con ello el riesgo tanto para las instituciones como para los consumidores de caer en sobreendeudamiento.

Quizá por falta de conciencia del consumidor o por descuido oportuno en el apetito de riesgo, el afán de liderazgo y rentabilización del sector o por parte de las instituciones el relajo en vigilar el cumplimiento de procesos, normas y reglamentaciones, que de un lado no cumplimos y del otro no hacemos cumplir o simplemente no informamos que existen a quienes toman dichos créditos, al consumidor.

La realidad señala que en momentos económicos de crecimiento de un país, las instituciones financieras aprueban créditos a muchos agentes consumidores que en otros momentos no recibirían las mismas oportunidades y descuidan los procesos de prevención del riesgo, exponiendo las colocaciones a las modificaciones imprevistas del entorno económico inestable del país, lo que ocasionaría la elevación de los índices de morosidad, pudiendo llegar a niveles de pérdida total de los bienes adquiridos por el consumidor y más; pudiendo tornarse en una situación con panorama de riesgo general para el propio Sistema Financiero Nacional.

En el país tenemos distintos créditos de consumo que se ofrecen al consumidor, con publicidad intensa y con poca información, siendo que cada banco tiene una gran cantidad de tarjetas de crédito que ofrece, cada cual con preferencia en distintas casas comerciales, lo que incentiva al consumidor a tener varias a fin de tener beneficios en distintos lugares, resaltando que en muchos casos las tasas de costo efectivo anual llegan a más del 150\%.

Por otro lado, se indica la existencia de políticas comerciales que inducen al consumidor a obtener créditos sin que hayan sido solicitados previamente, con el envío de tarjetas al domicilio o el acceso a ofertas únicamente utilizando determinadas tarjetas, con lo cual impiden acceso a ofertas a consumidores que carezcan de una.

En el Perú, la sociedad por lo general tiene tendencias totalmente consumistas, eso se observa claramente cuando se revisa la información del creciente endeudamiento de los hogares.

Así mismo, a pesar de las diferencias en los ingresos de las personas, la mayoría accede a diferentes productos y servicios a través del crédito. El uso excesivo del mismo ha llegado a que se utilice no solo para compras de un bien o para obtener algún servicio sino también para la adquisición de artículos de primera necesidad como los alimentos, vestimenta, salud, etc, y lo que es aún más grave que muchas veces se utiliza el financiamiento mas largo para poder cancelar estos productos. 
Por otro lado, a pesar de la información brindada principalmente por la SBS sobre cómo manejar el endeudamiento, la población se sigue sobre-endeudando, esto también nos lleva a pensar que el consumidor peruano no se encuentra adecuadamente preparado para el uso de los productos de crédito, y que en muchos casos los clientes de los bancos y de las casas comerciales que otorgan líneas de crédito a través de las tarjetas no tienen conocimiento del reglamento que regula el mercado.

Otro problema existente es lo que pasa cuando el consumidor se ve imposibilitado de pagar, ya que en este caso la única propuesta que da la entidad financiera es el refinanciamiento, a su cargo o al de la entidad que hubiere comprado la deuda.

En ese sentido, una vez atrasado el consumidor en el pago, la entidad da por finalizado el contrato en las condiciones pactadas, y se permite hacer uno nuevo capitalizando la deuda más los intereses, lo cual el consumidor se ve obligado a aceptar a fin de no perder su estado crediticio y su acceso al mercado en general.

Estos intereses cobrados por las entidades que compran las deudas que los bancos dan por perdidas, no están siendo fiscalizados y superan ampliamente lo cobrado inicialmente por las entidades financieras. Pero lo curioso es que si bien los bancos venden las deudas a terceros, estos terceros muchas veces son empresas vinculadas a aquellos.

\section{Causas del sobreendeudamiento}

Las causas pueden ser tanto directas como indirectas, dentro de las más comunes podemos mencionar:

- Retiro de dinero en efectivo

- Carencia o poca información

- Compradores adictivos o compras compulsivas

- Despido o cese laboral

- Deudas comerciales no reportadas en las centrales de riesgo

- Disminución de ingresos

- Enfermedad / Fallecimiento

- Inflación

- Pagos aplazados

- Compra de deuda por reunificación de préstamos

- Algún tipo de crisis familiar

- Utilización del crédito para gastos innecesarios 


\section{Consecuencias del sobreendeudamiento}

Así mismo, el sobreendeudamiento repercute tanto en el consumidor como en su familia, originando las siguientes consecuencias:

- A nivel jurídico, un mal manejo de las deudas y no honrar los compromisos financieros trae como consecuencia el embargo de los bienes o patrimonios del deudor.

- A nivel país, los atrasos excesivos o un alto índice de deudas sin pagar puede ocasionar grabes problemas financieros en un país.

- A nivel macroeconómico, cuando hay un aumento excesivo en los atrasos o deudas sin pagar puede ocasionar que se eleven los diferentes tipos de interés, lo que afectaría el desarrollo del país.

- A nivel personal, el sobreendeudamiento puede afectar emocionalmente a las personas aumentando los niveles de estrés. Un mal manejo de la economía personal puede llevar a un estado de quiebra financiera.

- Ámbito Familiar, el sobreendeudamiento produce una disminución o pérdida del poder adquisitivo familiar lo que puede ocasionar crisis o conflictos familiares, afectando directamente la cobertura de las necesidades básicas como vivienda, alimentación, salud y vestuario.

- Ámbito Laboral, en este aspecto pueden ocurrir varias dificultades como por ejemplo enfrentarse a una presión en el centro de labores, algunas empresas por políticas internas exigen a sus trabajadores que no registren problemas en el sistema financiero, esto puede conllevar a una pérdida del empleo, así mismo, muchas de las empresas no toman personal nuevo si es que estos se encuentran con antecedentes negativos en las centrales de riesgos.

- A nivel del Sistema Financiero Nacional, como consecuencia del sobreendeudamiento pueden suspenderse o restringirse las líneas de crédito de los clientes, lo que puede ocasionar recortes en la actividad productiva, de operación y del consumo frecuente del endeudado.

- Del medio social hacia el consumidor endeudado, el sobreendeudamiento y el no honrar las deudas financieras puede ocasionar un bloqueo del consumidor endeudado frente a su entorno profesional, comercial y social. Por otro lado, también se produce una restricción en su participación con el sistema financiero, ya que el registrar antecedentes negativos puede generar cierres de cuentas, anulación de líneas de crédito, etc, restringiendo su intervención con el medio financiero.

- Del consumidor endeudado hacia el medio social, no cumplir con las obligaciones financieras produce la pérdida del acceso al consumo por parte del deudor y produce un perjuicio económico que se encuentra fuera de su control personal. En muchos casos el consumidor solicita refinanciamientos o reestructuración de sus deudas en búsqueda de una solución a sus problemas económicos pero estos pueden ocasionar mayores compromisos financieros que al no ser solucionados producen una pérdida del control frente a la situación de endeudamiento. 


\section{Algunas recomendaciones para evitar el sobreendeudamiento:}

1.- Para evitar el sobreendeudamiento o el riesgo de pagar más por los créditos adquiridos es necesario que las personas se endeuden en la moneda en que reciben sus ingresos (en nuestro caso en moneda nacional) para evitar la exposición a las variaciones del tipo de cambio.

2.- Es necesario fortalecer la capacidad de la sociedad civil a través de la capacitación de consumidores, y la sistematización de información relevante a ser difundida por entes representativos y/o asociaciones de consumidores.

3.- Contar con una fuente de ahorros para poder solventar cualquier imprevisto que se presente.

4.- También es importante contar con algún producto de seguros que pueda cubrir cualquier eventualidad.

5.- Cuando se tenga en uso una tarjeta de crédito es recomendable pagar siempre el monto total facturado y en casos muy puntuales el mínimo requerido.

6.- Evitar siempre endeudarse a mediano o a largo plazo cuando se trata de consumos básicos.

En conclusión, cuando la situación económica está y se anuncia favorable, baja el nivel de vigilancia de los agentes económicos y de las entidades financieras. Los clientes se relajan, las instituciones financieras también, es la "paradoja de la tranquilidad" de Hyman Minsky; ahí se van gestando los futuros problemas de sobreendeudamiento. Por otro lado, la exacerbación de la competencia hace que unos empiecen a relajar sus estándares y ganen cuota de mercado, los otros se sienten cada vez más obligados a imitarlos, presiones competitivas que provocan una espiral de malas prácticas.

El Perú en los últimos años vive uno de los mayores auges de acceso al crédito el mismo que está haciendo que hoy por hoy sin más requisito que una firma y un ingreso del salario mínimo vital los consumidores adquieran bienes y servicios a través del crédito. Si bien esto tiene beneficios, también trae perjuicios si no es manejado de manera responsable tanto por consumidores como por empresas y estado, pudiendo generar una crisis como las que hemos pasado al final de la década del 90.

La falta de información se presenta como uno de los problemas principales en el mercado, en el cual se resaltan únicamente los beneficios del crédito y no las condiciones y costos reales, los cuales conoce el consumidor una vez incluido en la relación de consumo. Asimismo, existe una ausencia de programas de capacitación a los consumidores sobre cultura financiera y manejo de finanzas personales, que permite la gran brecha de asimetría informativa existente entre los proveedores y los consumidores de este mercado. 


\section{REFERENCIAS}

\section{Referencia Normativa:}

LEY N²6702 - General del Sistema Financiero y orgánica de seguros y de la Superintendencia de banca, seguros y administradoras de fondos de pensiones./ ANEXO №1-CAP III

RESOLUCION-SBS-1237-2006 - Reglamento para la Administración del Riesgo de sobreendeudamiento de Deudores Minoristas / ANEXO N"02-A-CAP III

RESOLUCION-SBS-6941-2008 - Reglamento para la administración del Riesgo de sobreendeudamiento de Deudores Minorista / ANEXO N02-B-CAP III

RESOLUCION-SBS-037-2008 - Reglamento de la Gestión integral del Riesgo /ANEXO N03-A-CAP III

RESOLUCION-SBS-3780-2011 -Reglamento de la Gestión integral del Riesgo / ANEXO N03-B-CAP III

RESOLUCION-SBS-11356-2008 - Reglamento para la evaluación y clasificación del Deudor y la exigencia de provisiones./ ANEXO N04-CAP III

RESOLUCION-SBS-264-2008- Reglamento de Tarjetas de Crédito / ANEXO Nº5-CAP III

\section{Referencia Conceptual:}

Asociación Peruana de Consumidores -aspec- (2016). Investigación para el grupo andino de consumidores. Lima.

Baca, G., A. (1997). "La Administración de Riesgos Financieros". Articulo tomado de la revista Ejecutivos de Finanzas, publicación mensual, Año XXVI, No. 11, Noviembre, México.

Bodie, Zwi y Merton,R. (1999). Finanzas. México: Editorial Pretince Hall.

Bonà, A. et al.(2007) Riesgo de Crédito: Amenaza u Oportunidad .Universitat Pompeu Fabra -IDEC, Máster en Mercados Financieros, Sexta edición.

Consorcio de Organizaciones Privadas de Promoción de Desarrollo de la Pequeña y MicroempresaCopeme-, (2011). Microfinanzas en el Perú .Reporte de mayo 2011. Recuperado de http:// mixmarket.org/mfi. COUNTRIES \& REGIONS.

Díaz, J. y Hernández, F. (1996). Futuros y opciones financieros. México: Edita Limus.

Comisión de Basilea de Supervisión de Bancos (1999,30Nov). Principios para la administración de riesgos. Documento consultivo, Basilea, Julio de 1999.

CSFI Centre for the Study of Financial Innovation. (2011) Riesgo en las micro finanza: perdiendo su magia. .Encuesta "Banana Skins" sobre Micro finanza. Patrocinado por Citi Group, CGAP. 
Economices Instituto of Bard College, Working Paper 74.

Fragoso, J.C. (2002). "Análisis y Administración de Riesgos Financieros". Exposición de la materia de Análisis de Riesgos, de la especialidad en Economía Financiera de la Universidad Veracruzana, Capítulo 13: Mercado de Derivados, Xalapa.

Jorion, P. (1999). Valor en riesgo. México: Limusa.

Krugman. y Obstfeld, M. (1995). Economía Internacional. España: $3^{a}$ Edición, Editorial McGrawHill.

Levi, D. Maurice (1997). Finanzas Internacionales. 3a Edición. México: Editorial McGraw-Hill. .

Lewent, J., y Kearney,J. (1990a). "Identifying, measuring, and hedging currency risk at merck". Continental Bank Journal of Applied Corporate Finance 2, pp. 19-28; EE.UU.

Minsky B,P. (1992): "The financial instability hypothesis". The Jerome Levy

Páscale, R. (1999a). Decisiones financieras. Argentina: $3^{a}$ Edición, Ediciones Machi.

Prada, F. (2015a). Causas y consecuencias del sobreendeudamiento .Foro Nacional Internacional. Recuperado de www.monetos.es

Mendonça F.,S. (2005). Guía de planeamiento estratégico para Instituciones de Micro finanzas. (5a Versión, para edición).

Reporte de Estabilidad Financiera BCR (2016).

Trujillo, I. (2003 a) El sobreendeudamiento de los consumidores. Granada: Editorial Comares.

Levi, D. Maurice (1997). Finanzas Internacionales. 3ª Edición. Editorial McGraw-Hill. México.

Lewent,J. y Kearney,J. (1990b). "Identifying, Measuring, and Hedging Currency Risk at Merck". Continental Bank Journal of Applied Corporate Finance 2, pp. 19-28; EE.UU.

Minsky H.,P. (1992): "The Financial Instability Hypothesis". The Jerome Levy

Pascale, R. (1999b). Decisiones Financieras. 3a Edición, Ediciones Machi, Argentina

Prada, Fernando. (2015 b). Causas y consecuencias del sobreendeudamiento .Foro Nacional Internacional. ww.monetos.es

Mendonça F., S. (2005b). Guía de Planeamiento Estratégico para Instituciones de Micro finanzas. (5ª Versión, para edición).

Banco Central de Reserva (2016) Reporte de Estabilidad Financiera. Lima

Trujillo, I. (2003 b) El sobreendeudamiento de los consumidores. Granada. Editorial Comares. . 


\section{CONSTITUCIÓN POLÍTICA DEL PERÚ}

Artículo $65^{\circ}$.- El Estado defiende el interés de los consumidores y usuarios. Para tal efecto garantiza el derecho a la información sobre los bienes y servicios que se encuentran a su disposición en el mercado.

Asimismo vela, en particular, por la salud y la seguridad de la población.

SBS www.sbs.gob.pe

BCR www.bcr.gob.pe

Diario Gestión www.diariogestión.com.pe

Equilibrium S.A www.equilibrium.com.pe

Memoria Anual BCP

Memoria Anual Interbank

Memoria Anual BBVA Continental

Memoria Anual Scotiabank

Norma General Del Sistema Financiero Legislación General del Sistema Financiero Ley Nro. 26702 Norma General Del Sistema Financiero Legislación General del Sistema Financiero Ley Nro. 26702

Normas que Regulan el Sobreendeudamiento, Resolución S.B.S Nro. 6941-2008. Lima, 25 de Agosto del 2008: Se aprueba el Reglamento para la administración del riesgo de sobreendeudamiento de deudores minoristas 